\title{
Largely improved tensile properties of chitosan film via unique synergistic reinforcing effect of carbon nanotube and clay
}

\author{
Changyu Tang, Lixue Xiang, Juanxia Su, Ke Wang, Changyue Yang, Qiang Fu*1 \\ Department of Polymer Science and Materials, Sichuan University, State Key Laboratory of \\ Polymer Materials Engineering, Chengdu 610065, China
}

Modification of glass plate. Modification of glass plate is convenient for peeling off the film from the glass plate. The hydrophobic reagent is prepared by dissolving $20 \mathrm{ml}$ Dimethylchlorosilane in $60 \mathrm{ml}$ acetone without water. The mixed solution above was cast into the hydrophilic glass plate and reacted with glass plate at $150{ }^{\circ} \mathrm{C}$ for 3 h.Then, The hydrophobic glass plate was washed with alcohol for several times.

Acidification of raw MWNTs. The raw carbon nanotubes were sonicated in $400 \mathrm{ml}$ of mixture acid solution for $1 \mathrm{~h}$ (in a laboratory ultrasonic cleaner, $59 \mathrm{kHz}, 200 \mathrm{~W}$ ) and were further heated at $50{ }^{\circ} \mathrm{C}$ for $24 \mathrm{~h}$. Upon cooling, the resultant suspension was centrifuged in eight polypropylene tubes at $4000 \mathrm{rpm}$ for $15 \mathrm{~min}$. The supernatant acid was decanted, replaced by distilled water, and vigorously shaken to suspend the solids, followed by a second centrifuge-decant cycle. Then the solids were mixed with $500 \mathrm{ml}$ of distilled water, and filtered through a $0.45-\mu \mathrm{m}$ pore size cellulose membrane. (Ya xin purification equipment factory, Shanghai) The residue was washed with distilled water until no residual acid was present, and then dried in a vacuum oven at $50{ }^{\circ} \mathrm{C}$ for overnight.

Preparation of the nanocomposite films All chitosan nanocomposites with different fillers content were prepared by solution blending. A typical procedure of chitosan ternary nanocomposite containing $3 \mathrm{wt} \%$ of clay and $0.4 \mathrm{wt} \%$ of CNTs is as follows: $1 \mathrm{~g}$ chitosan powder was dissolved in a $40 \mathrm{ml} 2 \%(\mathrm{v} / \mathrm{v})$ aqueous acetic acid solution using a laboratory magnetic stirrer at $200 \mathrm{rpm}$ for $1 \mathrm{~h}$, and filtered through the filter paper to remove the impurity.30 mg clay and $4 \mathrm{mg}$ CNTs are ultrasonicated for $15 \mathrm{~min}$ in $40 \mathrm{ml}$

\footnotetext{
1 *Corresponding author, Tel: +86-28-85460953, Email: qiangfu@ $@$ scu.edu.cn
} 
distilled water using ultrasonication tip( CF-300,50 khz,150 w, Southwest applied Acoustics Institute, Sichuan, China),respectively. Then, the clay suspension was added into the chitosan solution,followed by stirring at $60{ }^{\circ} \mathrm{C}$ for $5 \mathrm{~h}$. Subsequently, CNTs suspension was added into the mixture solution with stirring for $1 \mathrm{~h}$. The resulting solution volume is controlled to $50 \mathrm{ml}$ by evaporating water. The solutions were degassed for $3 \mathrm{~h}$ under vacuum. After that, chitosan/clay/CNTs solutions were poured into a hydrophobic glass plate and dried at $50{ }^{\circ} \mathrm{C}$ to remove the solvents. The films were kept in an oven at $50{ }^{\circ} \mathrm{C}$ to remove the remaining water for $5 \mathrm{~h}$ before mechanical test. Mean thickness of the films were about $0.1 \mathrm{~mm}$. 


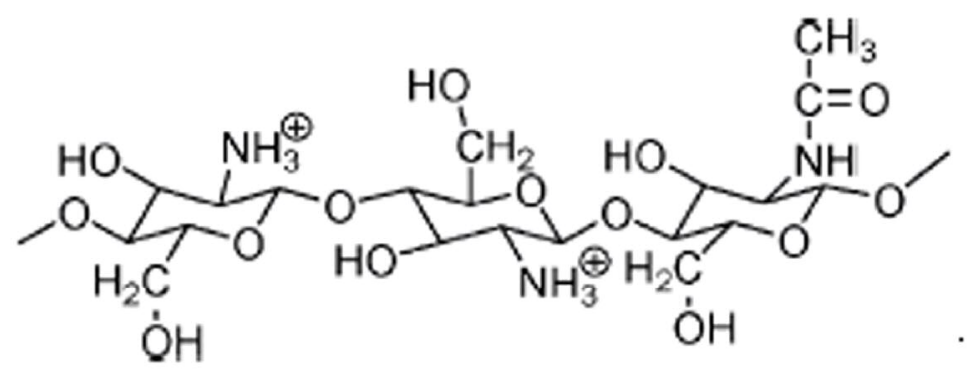

Figure S1. Chemical structure of chitosan in acid media

\section{FTIR Experimental Results}

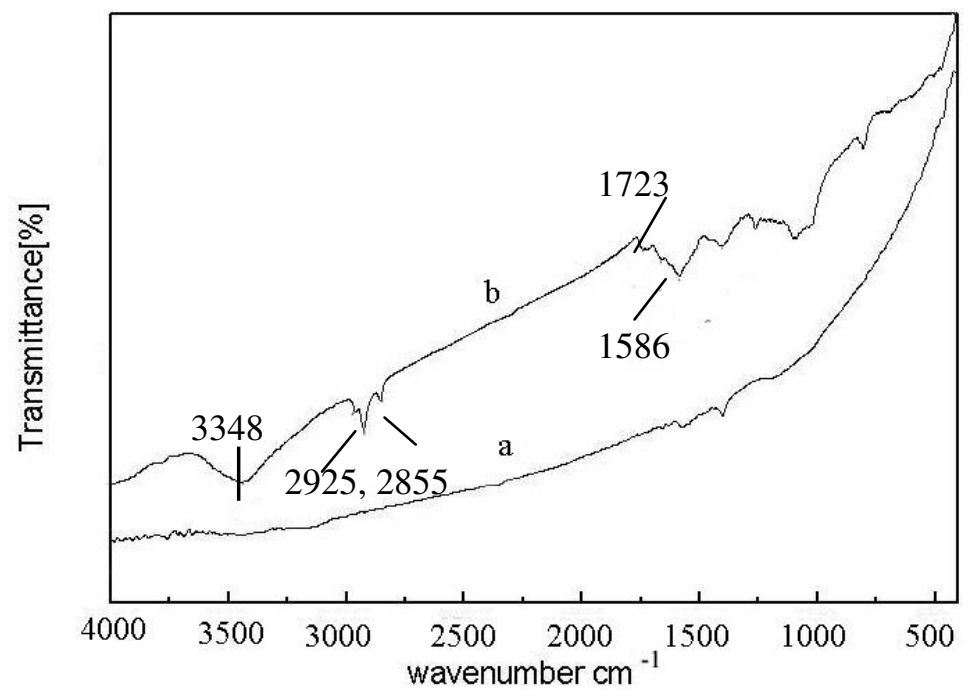

Figure S2. FT-IR spectra of (a) raw MWNTs and (b) acidified MWNTs.

Data for MWNT-COOH (KBr): $3448 \mathrm{~cm}^{-1}(\mathrm{~m}, \mathrm{OH}), 2925 \mathrm{~cm}^{-1}(\mathrm{w}, \mathrm{CH}), 2855 \mathrm{~cm}^{-1}$ (w, $\mathrm{CH}), 1723 \mathrm{~cm}^{-1}(\mathrm{~m}, \mathrm{C}=\mathrm{O}), 1586 \mathrm{~cm}^{-1}(\mathrm{~m}, \mathrm{C}=\mathrm{C})$. 